\title{
From Public Value to Social Value of Digital Government: Co-Creation and Social Innovation in European Union Initiatives
}

\author{
Andrea Halmos \\ European Commission, DG \\ CONNECT \\ Andrea.Halmos@ec.europa.eu
}

\author{
Gianluca Misuraca \\ European Commission, JRC \\ gianluca.misuraca@ec.europa.eu
}

\author{
Gianluigi Viscusi \\ École Polytechnique Fédérale de \\ Lausanne (EPFL) \\ gianluigi.viscusi@epfl.ch
}

\begin{abstract}
This paper discusses the development of key features in European Union policy and service redesign, based on social innovative practices where cocreation and the related phenomenon of digital social innovation have a high potential impact. The idea underneath this claim is that Information and Communication Technologies are becoming increasingly pervasive in the design, development and delivery of social innovation and co-creation initiatives which should not be limited to service delivery, rather serve as the driver for opening-up governance systems and change the way public organizations are structured and policy designed and implemented. Consequently, the paper discusses the key elements identified for setting up open and collaborative governance systems, while, taking stock from the analysis of policy experiences and practices funded by the European Commission, an overview of main drivers and barriers are presented. The paper concludes outlining recommendations for future research, as well as implications and possible directions for policy.
\end{abstract}

Keywords: Co-creation, Social Innovation, ICTs, Governance, Public value

Disclaimer: The opinions expressed are those of the authors and do not necessarily reflect those of the European Commission

\section{Introduction}

The rapid transformation of our society, complex challenges and the digital revolution, along with budgetary pressures for governments and the future of public services, created a new momentum for the modernization of public administrations.
In fact, while pressing sustainability problems and inequalities are increasing in the world, the unprecedented hyper-connectivity offered by the Internet creates powerful opportunities to reduce such inequalities, if harnessed through open platforms which can create possible collective solutions to sustainability problems. Unlike more straightforward issues that can be resolved simply with enough political will, particularly through government activities, sustainability can emerge from virtuous circles involving everyone, from decision makers to businesses and citizens.

In this perspective, the European Commission's DG CONNECT has funded many research and policy support actions aimed at developing and piloting innovative solutions for co-creation of public services and creating open collaborative platforms for social innovation, experimenting with open data and emerging networking technologies. At the same time research conducted by the European Commission's Joint Research Centre in collaboration with DG Employment Social Affairs and Inclusion over the period 2014-2017, provided a deeper understanding of how EU Member States can make better use of Digital Social Innovation to provide better and more efficient social services and increase the well-being of citizens [54].

Within this context, co-creation or co-production means delivering public services in an equal and reciprocal relationship between professionals, people using services, their families and their neighbors. Where activities are co-created in this way, both services and neighborhoods become far more effective agents of change. [52:9]. Within the literature on this topic, some authors position cocreation in public services as part of a new regime for public policy implementation, sometimes hypothesized to be a New Public Governance [65, 66], that follows Old Public Administration (OPA, essentially Weberian bureaucracy) and the New 
Public Management movement that embraced the application of private sector models to the public sector $[25,39,75]$. In contradiction, others ass ert that the underlying assumptions behind the majority of discussions of co-creation in the context of public services have been based on the simple customerservice provider relationship taken from the commercial realm with little or no consideration of the specificity of the public sector compared to the private sector, especially the role of politics or policies defining the context of service delivery [5, 19, 67]. The reality is vastly different and more recently it has been combined with the debate on Social Innovation, especially when enabled by Information and Communication Technologies (ICTs).

Social innovation relates in fact to "new responses to pressing social demands, which affect the process of social interactions. It is aimed at improving well-being." [28:6]. It also refers to "new ideas (products, services and models) that simultaneously meet social needs (more effectively than alternatives) and create new social relationships or collaborations" [26:9]. ICT-enabled social innovation is then defined as a "new configuration or combination of social practices providing new or better answers to social protection system challenges and needs of individuals throughout their lives, which emerges from the innovative use of Information and Communication Technologies (ICTs) to establish new relationships or strengthen collaborations among stakeholders and foster open processes of co-creation and/or re-allocation of public value" [54:5].

The rationale underlying this paper is thus based on the central argument that using digital solutions in co-production of services can empower citizens and create new social interactions and practices where citizens not only contribute to public-service delivery in novel ways, but can do it more collectively [11].

The aim of this paper is to assess how social innovation and co-creation initiatives can serve as a driver to change governance and the structure of public organizations. To this end, we discuss the development of important features in EU policy and service redesign, based on socially innovative practices where co-creation and digital social innovation have a particularly high potential impact.

To better assess the potential of such initiatives, and building on previous analyses and policy reviews, the paper presents first (in Section 2) the theoretical background underlying the research, and the methodological approach followed (Section 3). Section 4 provides then an overview of the Case study under investigation, which is a comprehensive set of policy support and research activities funded and conducted by the European Commission, in collaboration with EU Member States. Section 5 concludes discussing the results of such analysis, outlining recommendations for future research, and implications and possible directions for policy.

\section{Theoretical Background}

\subsection{Public and social value}

Value creation and capture is a key topic in management literature [47, 72], which has found its field of application in public management [33] with the distinction between business and economic values and other forms of value, suitable to adapt to the specific status of public organizations not primarily oriented toward profit $[45,49]$. In particular, the academic debate in public administration studies, including the ones more interested in e-government, has been polarized around the concept of public value $[3,4,10]$. Public value can be generally defined as the "value created by government through services, law regulations and other actions" [43:4], addressing issues such as equity, ethos and accountability [43] and involving an attention to the quality, importance, fairness in the provisions of services as well as the satisfaction by their users [57, 80]. Taking these issues into account, the use of information and communication technology (ICT) in the public sector has been considered a key factor for the creation of public value, thus connecting it to the development of the e-government under a citizen centered perspective [42]. As a consequence, not only the outcomes of the e-government initiatives but also the policies adopted can be evaluated in terms of the consequent increase of public administrations' capacity of producing public value [42]. Thus, public value considers mainly the value perceived by citizens when they access public services or interact with public organizations [2, 3], where nonetheless citizens may play different roles (e.g., citizens as users and citizens as operators of public administration) with different desired outcomes and (public) values [7, 16], likewise. Consequently, different frameworks have been proposed to evaluate the public value of e-government (see, e.g., [21, 78]). Also, public value has been considered a suitable paradigm to study ICT-enabled public sector reforms and innovation $[18,32,58]$. In general, public value seems to concern the evaluation of the outputs of public administration, policies, services, and finally politics. However, an alternative stance of public value, extending its definition, allows to focus on outcomes rather than outputs, thus leading to a move form public to social value [23,61], questioning not 
only "What does the public most value?" but also "What adds value to the public sphere?", as pointed out by Benington [25]. As argued by Viscusi et al. [81] social value, concerns values for the society at large [2], and the evaluation of the public administration contribution to society [2,27] focused, e.g., on the improvement to quality of life and wellbeing [76]. In this context, initiatives such as the ones related to open government data may provide policy makers access to the information on these issues for a given population, as well as individual to balance or design new policies, services, and politics with sustainable public as well as social value [41,81]. A focus on social value implies a blurring of the organizational boundaries of public administrations opening them up to co-creation processes involving external actors (either organizations or individuals), with consequent needs for an understanding of these new relationships as well as interactions, also enabled by the use of the ICT as leverage for social value creation, capture, and innovation [15, 45, 59].

\subsection{Co-creation}

Co-creation as the idea of opening up organizational boundary to allow external users to contribute to the production of products, services, or science development received a growing attention in the last two decades from management and social scientists $[1,17,40,46,70,71,73,74]$. However the research on co-creation is still evolving, and clear-cut identification of its main characteristics is still under debate, the definition provided by Ramaswamy and Ozcan in a 2018 article [74] provides a comprehensive summary of them, considering cocreation as "enactment of interactional creation across interactive systems-environment (afforded by interactive platforms), entailing agencing engagements and structuring organizations" [74:200]. Considering now the public sector, cocreation is not a brand new concept [24] as contracting out or philanthropy have demonstrated how governments have always worked with both the private and third sector [68]. More recently, the cocreation-related idea of co-production has entered the (public) management and policy arena, referring to public services that are co-produced by labor which may be paid, unpaid, or paid below the market value $[13,34,69]$, yet representing a way for public administration to produce public value, likewise [19]. However, with regard to these issues, what is actually new is the availability and pervasiveness of effective means to facilitate such collaboration in the digital transformation process [20], such as underlying digital tools, platforms, and technologies (encompassing open and big data, open services, and evidence based decision-making processes) that are crucial to enable co-creation related initiatives to foster public value as well as social value and innovation.

\subsection{ICT-e nabled Social innovation}

Innovation may refer either to the output or the process itself that realises a new idea, leading to a change in practice that creates some kind of value, [48]. In the public sector this change can concern the way it functions or the way it exerts its role as well as their effects on the innovation of the private sector [38]. As to these issues, in the last twenty years a significant effort has been devoted to the use of the ICT for developing e-government and its evolution toward open government $[6,36,37,51,79]$, thus linking to it a main part of the innovation in the public sector. However at the state of the art there are claims and arguments that ICT has the potential to increase innovation [44, 64], the evidence of its impact is still limited [53, 77]. Yet, in this article we claim that the evolution of the use of the ICT and the shift towards openness in the public sector and services [12] may provide expected outcomes by moving from a public value orientation typical of egovernment through the actual enforcement of cocreation dynamics for social value and the consequent focus on enforcing social innovation. Often recognized as a 'quasi-concept' $[8,54]$ the research on social innovation cannot be ascribed to any paradigm in social science [83], actually encompassing economics, political science, sociology, social policy, and cultural studies [60]. Among the different definitions of social innovation, in this article we follow the perspective promoted by the European Union [27] on the basis of [62], considering social innovation as social in its own ends and means, producing new ideas in products, services, and models that meet social needs and create new social relationships and collaborations. Accordingly, strictly related to social innovation are social services, ranging from statutory and complementary social security schemes covering the main risks of life to services provided directly to the person for, e.g. social assistance, employment and training, childcare, social housing or long-term care for elderly and for people with disabilities [54].

These social services have a role in improving quality of life as well as well-being, playing also a prevention and social cohesion role [54]. Consequently, as for the relevance of value cocreation and co-production, citizens' involvement in the design, production and delivery of public services 
is considered as a cornerstone for social innovation in the public sector $[8,63]$, where ICT plays a key role as enablers especially with regard to the challenge of guaranteeing resilience, likewise [56].

\section{Method}

The article follows an interpretive perspective [82], aiming to elicit an understanding of how cocreation and social innovation have been related to innovation enabled by the ICTs and to figure out their role in a potential evolution of digital government, likewise. Accordingly, the presented case study [9, 84] has an interpretive stance, which nonetheless adopts a longitudinal or historical perspective [50] as background for the development of the flow of the argument. To this end, an analysis has been carried out on the actions and initiatives promoted and developed in a specific context, the European Union, from 2010 to 2018. The analysis has been based on archival documents, reports, and the direct experience of two of the authors in the organizations in charge of policy design and program development for the considered stream of initiatives. Thus, the analys is has considered the actions of the case study along their different components, from their design as proposals to their development, and to their evaluation and impact. Finally, the third author acted as external discussant and participant to the hermeneutic process leading to the development of the arguments for this paper and of the selected case study.

\section{Case Study}

The European Commission has been working with Member States on e-government for more than a decade. The past and present EU e-government Actions Plans have been the political instruments to advance the agenda of ICT-enabled public sector modernization across the EU.

The exponential growth in digitalization, increased information and knowledge exchange, enhanced connectivity, openness and transparency are leading to a radical change in citizen expectations. Citizens are changing their approach to interacting with, and relating to, governmental organizations and services. At the same time, new technology is helping citizens become more 'prosumers' in many facets of life, contributing with their resources to also help address the needs for example of their own communities. Technology allows them to take control of their own health by using wearable sensors, improve their own ecological footprint by using smart meters or take better control of their own data. A fundamental issue to consider is how public policy and public administrations should handle such bottom-up and non-traditional activities which are instrumental to tackle social challenges.

In this particular context, the European Commission saw an opportunity in the digital transformation and argued for a complete re-thinking of public service delivery, breaking them into reusable, modular services that could be, along with government data, shared among administrations and combined in innovative ways both by administrations and by citizens, businesses or civil society.

The 'Vision for public services' non-paper [29] proposed to approach the modernization of public adminis trations through the policy design of open and collaborative government model, based on the principles of collaboration, transparency and participation. The underlying vision thus encouraged to open up government data, services and decisionmaking processes both between administrations (for a joined-up government user experience) and eventually to third parties (for the creation of innovative services and engagement in policymaking).

Focusing on the necessary internal changes within government, the concept paper provided the basis for many policy actions, such as project funding through the Horizon 2020 Research and Innovation Framework Programme -, studies, workshops and subsequently the e-government Action Plan 20162020 [30]. Over the period 2014-2017, over ten European projects have piloted the co-creation of public services, while others have advanced on the methodology of co-creation. They cover mostly local administrations as piloting sites, from almost all EU Member States, with Germany, Italy, Netherland, Spain and the UK more than one city. Environmental issues have always been an important area where co-creation can emerge.

As regards their development, most projects have tested local, urban services, such as for example land use planning, street cleaning, bike sharing, improving walks, transport timetables and tree cadaster. A number of local services aimed at administrative services such as permits or regulation for planning. Another large portion of the projects addressed human services, such as health care - working with issues such as better healthcare services for migrants, reducing childhood obesity, people with disabilities as well as social care - including unemployment policies, housing, redesigning local social services or childcare services. 
All projects have benefitted from the availability of data; mostly combining various open datasets or service building blocks for the creation of new, user-friendly services, while some projects have also used data to visualize certain information or collected data from users, including social media and behavior analytics. Although digital tools have been key to for example set up collaboration platforms, engage with citizens or make re-usable datasets, service building blocks or apps available to users; most projects have experienced that these tools and methods were also complemented by face-to-face meetings. In addition to these projects, almost 400 open government use cases were analyzed [14], many of which also applied co-creation practices. The majority of cases relied on opening up government assets and public services and have covered all phases of the delivery lifecycle (design, implementation, monitoring and evaluation).

Furthermore, the recently organized workshop on 'Digital Transformation of Public Administrations', which invited all these projects to evaluate the success of their project and share their experiences, found 'open, modular, collaborative government' beneficial, as it can lead to greater efficiencies, improved service delivery, innovative solutions, increased citizen engagement and in general more collaboration, participation and transparency.

According to the report's findings "co-creation of services and applications represents a key approach, making government more relevant and services closer to citizens' needs, increasing the take-up of open government in the EU" [31:15]. It is however observed that the readiness level of public administrations to "welcome promising innovations relying to co-creation" is still limited, thus making incentives essential [31:12].

At the same time, while pressing sustainability problems and inequalities are increasing in the world (see the United Nations Sustainability Development Goals), the unprecedented hyper-connectivity offered by the Internet can offer powerful solutions to reduce such inequalities, if harnessed by the people and for the people, through open platforms which do not naturally favor the accumulation of data and value in a few private platforms. These open platforms create a better awareness of what peers are doing, and of the possible collective solutions to sustainability problems. Unlike more straightforward issues that can be resolved simply with enough political will, particularly through government activities, sustainability can only emerge from virtuous circles involving everyone, from decision makers to businesses and citizens. The objective of the European Commission was to explore ways to steer stakeholders with diverging interests towards the same objective. To test possible solutions, in 2013 the Commission launched the Collaborative Awareness Platforms for Sustainability and Social Innovation (CAPS) initiative.

CAPs have been implemented though three calls for research and innovation projects piloting new open and collaborative approaches to solving sustainability challenges in environmental, economic or social areas, such as open policy making, open democracy, citizen science, collaborative consumption, collaborative economy, or collaborative making. Whereas the calls were very broad in terms of the possible topic to be addressed, the methodology required very specific characteristics: using innovative combinations of open networking technologies (i.e. based on open source, open hardware or open data), adopting a truly multidisciplinary approach (supported by the presence of at least 2 non ICT organizations in each successful consortium) and involving from the beginning an existing large community of interested users, such as local communities and civil society in general.

Through a series of projects funded by the H2020 Research and Innovation Program, CAPs is betting on new concepts of online platforms to raise awareness and generate collaborative solutions. Also, it is supporting the growing will of constituencies as well as associations, NGOs, etc. to co create and to ensure that their voice is being heard, considered, and eventually make impact on their daily life. The CAPS movement supported through the EC's research and innovation budget is definitely one of the potential game changers for society in Europe and in the world.

\section{Discussion and conclusions}

As most of the co-creation activities are initiated by public administrations, top-down, administrations themselves have a key role in creating the enabling environment that will foster co-creation. From an organizational point of view, low threshold to participate, simple processes, with language talking to the citizens are important as well as ensuring inclusiveness, fairness and transparency. In order to succeed in the adoption and effective promotion of collaborative services, a change in government and 
institutional culture is required. Public administrations need to adjust their internal processes; empower their civil servants and incentivize the co-creation approach [28, 29].

Public administrations need to create the appropriate governance structures; linking and integrating the worlds inside government, but also with those outside government. This also means that "public administrations need to assume some new roles; set rules, provide guidance and incentives for collaboration and co-creation. They need to develop and apply open methodologies, license agreements, and methodologies for collaborative public service design". For this, there is a need for empowered civil servants with the right skills, who can also ensure favorable conditions for sustainable service production. Indeed, appropriate sustainability models would constitute important enablers. For example, emerging hybrid business models, building on service agreements as the basis for digital service delivery and combining elements of the public, private and social sectors could represent a relevant opportunity to boost public service level. Other business models include among others, advertisement-based approaches, public-private partnerships, public voluntary sector partnerships, social enterprises and others [29:11].

At the same time, digital technologies and the data they generate can greatly improve the necessary conditions for engagement. In this regard, open data, reusable or shared solution building blocks as well as standards and technical specifications have been identified as main technology-related enablers [14].

Another key enabling factor, that can also be a barrier, is the meaningful participation of users in the co-creation processes (social capital). The involvement of citizens may depend on their extrinsic or intrinsic motivation; whether they expect economic rewards or join the activity for self-interest and the sake of participating. The latter requires special conditions; trust in the participatory approach, trust in public institutions, but also civic capacities, administrative skills as well as sense of ownership.

Furthermore, citizens need to believe that they will indeed make a difference through their engagement. Citizen engagement may be relevant both at individual level (for example, separating garbage), but also collectively, in case of collaborative service creation for a specific community or user group with particular needs [22].

Some of the most prominent barriers to cocreation are related to the availability and quality of open data, including its accuracy, quality and reliable access to such data sets. This as well as more visibility about such data sets would allow for a more dynamic re-use of data. To facilitate this, local administrations, where most of the co-creation takes place, should have an open data policy in place that prescribes how to manage open data release. A current study aims to gain an understanding of the use of application programming interfaces (APIs) in digital government and their added value and to assess the feasibility of establishing a European API framework for digital government.

To unlock the economic potential of open data, it is important that measures are taken on the supply side to make high-value datas ets truly open for reuse. This means among others that governments prioritize their open data efforts by identifying high-value datasets, and make sure that these are available under an open license, in (multiple) machine-readable formats, can be reused without restrictions, and can be easily found on data portals based on standardized metadata descriptions.

Another hindering factor is the exploitation uncertainty. An important question is who owns the development process, and to which extent different levels of organizations were supporting the activities. It is also important to support the full co-creation lifecycle to ensure long-term sustainability of the cocreated services; including possibly co-maintenance and co-business, but so far this option has been rarely explored. Several studies and workshops have found, on one side, that barriers to a wide-scale implementation included, among others, lack of leadership and political commitment, lack of institutional and individual capabilities and skills, legal constraints, technological constraints (e.g. lack of standard APIs), uncertainties regarding sustainability and business models, legal uncertainties regarding responsibility and accountability, difficulties identifying citizens' needs or poor data quality [14].

Another barrier was the limited information on the cost and benefits of collaboration. When analyzing the value of new generation of egovernment services, the study presented in [35] found that while administrative services required high investments linked to reorganization across all government, they were scalable through automation and thus could lead to cost savings. Human services required moderate costs, often based on open source modules and were very important for improving service quality, reaching out to people and building trust, yet easier to replicate than to really scale up. As regards participatory decision-making services, the study found that they involved moderate technological costs, were crucial for building trust, while their scalability and replicability were limited, 'return on investment' was however significant, 
although difficult to quantify and more visible over the long run [14].

In conclusion, the exponential growth in digitization, increased information and knowledge exchange, enhanced connectivity, openness and transparency are leading to a radical change in citizen expectations. Citizens are changing their approach to interacting with, and relating to, governmental organizations and services. Traditional top down approaches to governing and policy making, which formed the basis of our understanding of states and politics in the 20th century, are increasingly questioned. Existing governance frameworks do not seem to grasp this complexity and uncertainty. The evolving complexity of European society needs to be faced and analyzed in order to identify adequate future Governance models to promote across the EU.

To foster the open government movement toward its next phase of maturity, there is a need to understand the governance models and their role in implementation. The above described co-creation could lead to administrative burden reduction, but also to data and intelligence-driven service personalization. This approach could see users dynamically composing services from existing service components, for example on the basis of the user's own profile or life events. This could facilitate the collaborative design, creation and delivery of services, in particular for the 'everyday', local, and location-driven services, based on open data and mobile devices or web-based services, using realtime data. In order to facilitate this, there should be a clear framework for co-creation, considering quality of service a priority (especially for what concerns accountability) together with the governance and exploitation of the input of citizens for policy making and new services design. Accordingly, it is also necessary to have a significant evidence base showing the benefits of collaboration in service design and delivery. In this regard new types of financing, sustainability and business models should be explored and further researched.

As often the ecosystem in which such initiatives take place is characterized by micro-socialenterprises or not-for-profit organizations that have little or no access to traditional financial mechanisms; thus, "new inter-sectoral governance models" may be an effective means to help the sustainability of these initiatives [55]. The European Fund for Strategic Investments (EFSI) supports social entrepreneurship through innovative mechanisms developed under the new EFSI Equity Instrument. The EFSI impact investing pilots engage and support social impact investors in providing risk capital financing to social enterprises in their early, growth or expansion stage. Research to assess the return of such investments, both in terms of their economic and social value, should be strengthened. In this process ICTs often play a game-changing role in the development of platforms that support innovative partnerships and collaborative business models, impinging on the intrinsic characteristics of social innovation and digital governance.

In this perspective, future research is needed to study further initiatives at the regional and local level, especially at city level or neighborhoods within cities. A local focus of this kind would allow us to better understand the dynamics across sectors, and identify the factors enabling effective co-creation and social change.

\section{References}

[1] Afuah, A., and C. Tucci, "Value Capture and Crowdsourcing", Academy of Management Review(July), 2013, pp. 457-460.

[2] Alford, J., "Defining the client in the Public Sector: a social-exchange perspective", Public Administration Review 62(3), 2002, pp. 337-346.

[3] Alford, J., "Public Value from Co-production by Clients", In J. Benington and M.H. Moore, eds., Public Value - Theory and Practice. Palgrave Macmillan, 2011.

[4] Alford, J., and J. O'Flynn, "Making Sense of Public Value: Concepts, Critiques and Emergent Meanings", International Journal of Public Administration 32, 2009, pp. 171-191.

[5] Alves, H., "Co-creation and innovation in public services", The Service Industries Journal 33(7-8), 2013, pp. 671-682.

[6] Anderson, K.N., H.Z. Henriksen, and R. Medaglia, "Maturity models in the age of digital diversity: Bey ond the Layne \& Lee legacy", In I. Snellen, M. Thaens and W. van de Donk, eds., Public Administration in the Information Age: Revisited. IOS Press, Amsterdam, 2012, 205-220.

[7] Bannister, F., and N. Walsh, "The virtual public servant: Ireland's public services broker", Information Polity: The International Journal of Government \& Democracy in the Information Age 7(2,3), 2002, pp. 115128.

[8] Bekkers, V.J.J.M., L.G. Tummers, B.G. Stuijfzand, and W. Voorberg, Social Innovation in the Public Sector: An integrative framework. LIPSE Working papers (no. 1), Rotterdam, 2013.

[9] Benbasat, I., D.K. Goldstein, and M. Mead, "The Case Research Strategy in Studies of Information-Systems", MISQ Quarterly 11, 1987, pp. 369-386.

[10] Benington, J., and M.H. Moore, Public Value - Theory and Practice, Palgrave Macmillan, Houndmills, Basingstoke, Hampshire, UK, 2011. 
[11] Bovaird, T., and E. Loeffler, "User and community coproduction of public services and public policies through collective decision-making: the role of emerging technologies", In T. Brandsen and M. Holzer, eds., The Future of Governance - Selected Papers from the Fifth Transatlantic Dialogue on Public Administration. National Center for Public Performance (NCPP), 2010, 231-252.

[12] Boyne, G.A., "Sources of Public Service Improvement: A Critical Review and Research Agenda", Journal of Public Administration Research and Theory 13(3), 2003, pp. 367-394.

[13] Brandsen, T., and M. Honingh, "Distinguishing Different Types of Coproduction: A Conceptual Analysis Based on the Classical Definitions", Public Administration Review 76(3), 2016, pp. 427-435.

[14] Bremers, J., and W. Deleu, Towards faster implementation and uptake of open government, European Commission, Directorate-General of Communications Networks, Content \& Technology, 2016.

[15] Brickson, S.L., "Organizational identity orientation: The genesis of the role of the firm and distinct forms of social value", Academy of Management Review 32(3), 2007, pp. 864-888.

[16] Castelnovo, W., and M. Simonetta, "The Evaluation of e-Government Projects for Small Local Government Organisation", Electronic Journal of e-Government 5(1), 2007, pp. 21-28.

[17] Cohen, B., E. Almirall, and H. Chesbrough, "The City as a Lab: Open Innovation Meets the Collaborative Economy", California Management Review 59(1), 2016, pp. 5-13

[18] Cordella, A., and C.M. Bonina, "A public value perspective for ICT enabled public sector reforms: a theoretical reflection", Government Information Quarterly 29(4), 2012, pp. 512-520.

[19] Cordella, A., A. Paletti, and S. Maha, "Renegotiating Public Value with Co-Production", In C. Tucci, A. Afuah and G. Viscusi, eds., Creating and Capturing Value through Crowdsourcing. Oxford Univ. Press., Oxford, UK, 2018, 181-203.

[20] Couldry, N., "The myth of 'us': digital networks, political change and the production of collectivity", Information, Communication \& Society 18(6), 2015, pp. 608-626.

[21] Cresswell, A.M., G.B. Burke, and T.A. Pardo, Advancing Return on Investment Analysis for Government IT: A Public Value Framework, 2006.

[22] Davies, A., and J. Simon, The value and role of citizen engagement in social innovation, European Commission, DG Research, 2012.

[23] Department for Digital Culture Media \& Sport, The Public Services (Social Value) Act 2012 - An introductory guide for commissioners and policymakers, Department for Digital, Culture, Media \& Sport, UK, 2018.
[24] Development, O. for E.C. and, Together for better public services: Partnering with citizens and civil society, OECD Publishing, 2011.

[25] Dunleavy, P., and C. Hood, "From old public administration to new public management", Public Money \& Management 14(3), 1994, pp.9-16.

[26] European Comission, Empowering people, driving change. Social innovation in the European Union, 2010.

[27] European Commission, This is European social innovation, Brussels, 2010.

[28] European Commission, Guide to social innovation, DG Regional and Urban Policy and DG Employment, Social affairs and Inclusion, 2013.

[29] European Commission, A vision for public services, Directorate-General for Communications Networks, Content and Technology - Sustainable and Secure Society Public Services, 2013.

[30] European Commission, "EU eGovernment Action Plan 2016-2020: Accelerating the digital transformation of government (COM(2016) 179 final)”, In 2016.

[31] European Commission, Digital Transformation of Public Administrations Event Sustainability and Exploitation of Horizon 2020 eGovernment Projects Results, 2017.

[32] Feldman, M.S., Order without design: Information production and policymaking, Stanford University Press, 1989.

[33] Feldman, M.S., "Management and Public Management", The Academy of Management Journal 48(6), 2005, pp. 958-960.

[34] Filipe, A., A. Renedo, and C. Marston, "The coproduction of what? Knowledge, values, and social relations in health care", PLOS Biology 15(5), 2017, pp. e2001403.

[35] Galasso, G., G. Garbasso, G. Farina, et al., Analysis of the Value of New Generation of eGovernment Services and How Can the Public Sector Become an Agent of Innovation through ICT, European Commission, Directorate-General of Communications Networks, Content \& Technology, 2016.

[36] Gronlund, A., "Ten years of e-government: the "end of history' and new beginning", In M.A. Wimmer, J.-L. Chappelet, M. Janssen and H.J. Scholl, eds., Electronic Government: 9th IFIP WG 8.5 International Conference, EGOV 2010, Lausanne, Switzerland, Augtust/September 2010: Proceedings. Springer-Verlag, Berlin / Heidelberg, 2010, 13-24.

[37] Heeks, R., and S. Bailur, "Analyzing e-government research: Perspectives, philosophies, theories, methods, and practice", Government Information Quarterly 24, 2007, pp. 243-265 ST-Analyzing e-government research: Per.

[38] Hollanders, H., A. Arundel, B. Buligescu, V. Peter, L. Roman, and P. Simmonds, European Public Sector 
Innovation - Scoreboard 2013, Brussels, 2013.

[39] Hood, C., and R. Dixon, "What We Have to Show for 30 Years of New Public Management: Higher Costs, More Complaints", Governance 28(3), 2015, pp. 265-267.

[40] Jasanoff, S., "Technologies of humility: Citizen participation in governing science", In Communicating Biological Sciences. Routledge, 2016, 45-64.

[41] Jetzek, T., "Managing complexity across multiple dimensions of liquid open data: The case of the Danish Basic Data Program", Government Information Quarterly 33(1), 2016, pp. 89-104.

[42] Kearns, I., Public value and e-government, London, 2004.

[43] Kelly, G., G. Mulgan, and S. Muers, "Creating Public Value: An Analytical Framework for Public Service Reform

" - Discussion paper prepared by the Cabinet Office Strategy Unit, United Kingdom., 2002.

[44] Koellinger, P., "The relationship between technology, innovation, and firm performance-Empirical evidence from e-business in Europe", Research Policy 37(8), 2008, pp. 1317-1328.

[45] Kroeger, A., and C. Weber, "Developing a Conceptual Framework for Comparing Social Value Creation", Academy of Management Review 39(4), 2014, pp. 513-540.

[46] Kyprianou, C., "Creating Value from the Outside In or Inside Out: How Nascent Intermediaries Build Peer-to-Peer Marketplaces", Academy of Management Discoveries, 2018.

[47] Lepak, D.P., K.G. Smith, and M.S. Taylor, "Value creation and value capture: A multilevel perspective", Academy of Management Review 32, 2007, pp. 180-194.

[48] Link, A.N., and D.S. Siegel, Innovation, Entrepreneurship, and Technological Change, Oxford University Press, 2007.

[49] Magalhaes, G., and C. Roseira, "Open government data and the private sector: An empirical view on business models and value creation", Government Information Quarterly, 2017.

[50] Mason, R.O., J.L. McKenney, and D.G. Copeland, "An historical method for MIS research: Steps and assumptions", MISQ Quarterly 21, 1997, pp. 307-320 STAn historical method for MIS researc.

[51] McDermott, P., "Building open government", Government Information Quarterly 27(4), 2010, pp. 401413.

[52] Michaelson, J., S. Mahony, and J. Schifferes, Measuring Well-being - A guide for practitioners, nef (the new economics foundation), 2012.

[53] Misuraca, G., C. Codagnone, and P. Rossel, "From Practice to Theory and back to Practice: Reflexivity in Measurement and Evaluation for Evidence-based Policy Making in the Information Society", Government Information Quarterly 30, Supple, 2013, pp. S68-S82.
[54] Misuraca, G., C. Colombo, C. Kucsera, S. Carretero, M. Bacigalupo, and R. Radescu, ICT-Enabled Social Innovation in support of the Implementation of the Social Investment Package (IESI) - Mapping and analysis of ICTEnabled Social Innovation initiatives promoting social investment through integrated approaches to the provision of social, 2015.

[55] Misuraca, G., and D. Gagliardi, ICT-Enabled Social Innovation (IESI): A conceptual and analytical framework, TU Dortmund, 2017.

[56] Misuraca, G., G. Pasi, and G. Viscusi, "Social Innovation and Resilience: exploring the dynamics and impacts on the digital transformation of governance \& society", ICEGOV 2018 (11th International Conference on Theory and Practice of Electronic Governance), ACM, New York, NY, USA, (2018), 91-100.

[57] Misuraca, G., and G. Viscusi, "Digital Governance in the Public Sector: challenging the Policy-Maker's innovation dilemma", 8th International Conference on Theory and Practice of Electronic Governance (ICEGOV2014), (2014).

[58] Misuraca, G., and G. Viscusi, "Shaping public sector innovation theory: an interpretative framework for ICT enabled governance innovation", Electronic Commerce Research, 2015, pp. 1-20.

[59] Misuraca, G., G. Viscusi, and G. Pasi, "Digital Governance Challenges for ICT-Enabled Innovation of Social Protection Systems in the EU", IFIP EGOV and ePart 2016, 2016. http://infoscience.ep fl.ch/record/224011

[60] Moulaert, F., F. Martinelli, E. Swyngedouw, and S. Gonzalez, "Towards Alternative Model(s) of Local Innovation", Urban Studies 42(11), 2005, pp. 1969-1990.

[61] Mulgan, G., "Measuring Social Value", Stanford Social innovation Review(Summer 2010), 2010, pp. 38-43.

[62] Murray, R., J. Caulier-Grice, and G. Mulgan, The Open Book of Social Innovation, NESTA, Young Foundation, 2010.

[63] Nederhand, J., V. Bekkers, and W. Voorberg, "SelfOrganization and the Role of Government: How and why does self-organization evolve in the shadow of hierarchy?", Public Management Review 18(7), 2016, pp. 1063-1084.

[64] OECD, The Economic Impact of ICT, Measurement, Evidence and Implications, OECD, Paris, 2010.

[65] Osborne, S.P., “The New Public Governance?”, Public Management Review 8(3), 2006, pp. 377-387.

[66] Osborne, S.P., "Public governance and public services delivery: A research agenda for the future",, In S.P. Osborne, ed., The New Public Governance? Emerging perspectives on the theory and practice of public governance. Routledge, London; New York, 2010, 413428.

[67] Osborne, S.P., Z. Radnor, and K. Strokosch, "CoProduction and the Co-Creation of Value in Public Services: A suitable case for treatment?", Public 
Management Review 18(5), 2016, pp. 639-653.

[68] Osimo, D., K. Szkuta, R. Pizzicannella, et al., Study on collaborative production in eGovernment (SMART 2010/0075), Tech4i2 Ltd - European Commission, 2012.

[69] Ostrom, E., Governing the commons - The Evolution of Institutions for Collective Action, Cambridge university press, 2015.

[70] Pestoff, V., "Collective Action and the Sustainability of Co-Production", Public Management Review 16(3), 2014, pp. 383-401.

[71] Prahalad, C.K., and V. Ramaswamy, "Co-creation experiences: The next practice in value creation", Journal of Interactive Marketing 18(3), 2004, pp. 5-14.

[72] Priem, R.L., "A consumer perspective on value creation", Academy of Management Review 32, 2007, pp. 219-235.

[73] Ramaswamy, V., "Leading the transformation to cocreation of value", Strategy \& Leadership 37(2), 2009, pp. 32-37.

[74] Ramaswamy, V., and K. Ozcan, "What is co-creation? An interactional creation framework and its implications for value creation", Journal of Business Research 84, 2018, pp. 196-205.

[75] Riccucci, N.M., "The 'Old' Public Management Versus the 'New' Public Management: Where Does Public Administration Fit In?", Public Administration Review 61(2), 2002, pp. 172-175.

[76] Robeyns, I., "The Capability Approach: a theoretical survey", Journal of Human Development 6(1), 2005, pp. 93-117.

[77] Savoldelli, A., C. Codagnone, and G. Misuraca, "Understanding the e-government paradox: Learning from literature and practice on barriers to adoption", Government Information Quarterly 31, Supple(0), 2014, pp. S63-S71.

[78] Savoldelli, A., G. Misuraca, and C. Codagnone, "Measuring the Public value of $\mathrm{e}^{- \text {Government: The }}$ eGEP2.0 model", Electronic Journal of e-Government 11, pp. 373-388.

[79] Traunmüller, R., "Open Government and Electronic Government: Some Considerations", In A. Kö and E. Francesconi, eds., Proceedings of the 3rd International Conference on Electronic Government and the Information Systems Perspective (EGOVIS 2014). Munich, Germany, 2014, 201-207.

[80] Viscusi, G., C. Batini, and M. Mecella, Information Systems for eGovernment: A Quality-of-Service Perspective, Springer, 2010.

[81] Viscusi, G., M. Castelli, and C. Batini, "Assessing social value in open data initiatives: a framework", Future Internet 6(3), 2014, pp. 498-517.

[82] Walsham, G., Interpreting information systems in organizations, Wiley, Chichester, 1993.
[83] WILCO, "The WILCO Project: A summary of the findings", 2014. https://cordis.europa.eu/result/rcn/155745_en.html

[84] Yin, R.K., Case study research : design and methods (Fourth ed.), Sage Publications., 2009. 